\title{
Evaluation of Information Classification on Websites and Impact of Culture: A Cross Country Comparison of Information Classification
}

\author{
Ather Nawaz \\ Department of Informatics, Copenhagen Business School, \\ Howitzvej 60, DK-2000, Copenhagen, Denmark \\ an.inf@cbs.dk
}

\begin{abstract}
The structure of information classification has an important role in the usability of websites. A majority of cross cultural studies have emphasized on localized elements of interface design and termed them as cultural markers However, not many studies have pointed out on how the classification of information on the websites can be similar or different, especially for those communities who have recently joined the global community of the Internet. This research aims to investigate the information classification of users in different countries and compares it with information classification of a website. The study will evaluate how different demographical properties impacts on the information structure of websites. The study will also evaluate to what extent users' performance and productivity changes, when the information classification of website matches with the end users mental model.
\end{abstract}

\section{Basic information of $\mathrm{PhD}$ research}

PhD Supervisor: Torkil Clemmensen, Department of Informatics, Copenhagen Business School, Denmark. Email: tc.inf@cbs.dk

The Research area of my work: The research area of my work is usability and sub-area of my work is website Information classification using card sort in cultural context.

Brief description of research Topic: This research investigates the information classification of websites from a cultural perspective and compares the website information classifications with the users' mental model.

\section{Introduction}

Due to the abundance of information, it has become a challenging problem to track and retrieve information from institute, university or e-commerce websites. The challenge may however not be the same in different countries. One of the key issues in the design of websites is the information classification on websites. With the global penetration of the internet, especially into regions where computer use has hitherto been scarce, the diverse needs and perceptions of quality place a special demands 
upon the web page design and how information is placed [1]. The information organized in the correct location speeds up the information retrieval for the users and provides a good user experience of the website. In the cross cultural studies of websites, much of the work has focused on similarities and differences between Asia and the West and little work appears to have been done to investigate the usability, language bias, and structure of websites in those communities who have recently joined the global community of the Internet [2].

Our research adds the body of knowledge in the domain of information structure on the website and users' understanding with the information structure on the websites especially in those countries where there is not much research done. The research proposes how the information classification in the different countries has the properties that do not resemble to each other, despite the similarity of participants' years of study and age.

\subsection{Research Problem}

With the access of large amount of information on corporates, institutes and ecommerce websites, it is often a challenge to retrieve information on these websites. The challenge may, however, not be the same in different countries. A key issue in a good website design is the classification of the information on the website. If the website information is classified in a manner that fits well with the user's perception of the topic, then information retrieval on the website is efficient and may even be satisfying. Most of the cross-cultural studies of websites have focused on the usability, language biases, and structure of Asian and Western websites. Little work appears to have been done investigating the structure of the websites in communities that have recently joined the global Internet community. Furthermore it is not the technical aspects that are cumbersome but the mental model of the end users in a group that can be different from the information classification of the websites. In order to improve the information findability and performance of users, demographic diversity and its influence on information classification for the websites should be acknowledged.

The prior research addresses the issue by emphasizing on the interface design aspect of websites and cultural markers but did not stress on the classification criteria of contents. A few of the researches talk about the classification models on websites. The studies of Choong [3] shows how the users from two different locations have different mental models and conceptions about the classification of information. The studies address the cultural aspect of information classification but only highlight the Chinese and American perceptive on information classification.

\subsection{Research Question}

1. How is the perception of website structure similar and/or different in the countries that have recently joined the global community of internet?

2. How does the fit between the users' mental model and the website's information classification affects the information findability on the websites?

3. To what extent does the information literacy of technology interaction influences the perception of information classification on websites. 


\section{Method}

The research for my $\mathrm{PhD}$ is conducted in two stages. In the first stage, I collected the data from the users of a university website in Pakistan and Denmark. The first stage of the research helped me to identify the important and interesting factors of the research. I used brainstorming and card sorting technique to understand the users' mental model. Card sorting is a technique aligned with the Kelly's personal construct theory [4]. It assumes that people make sense of the world by classification and people can describe their own classification of the world with reasonable validity and reliability [4,5]. Card sorting is a useful way of involving users with the classification of information into groups. It provides an insight into users' mental models, illuminating the way they often tacitly group, sort and label tasks and content within their own heads[5]. The supplementary activities included information findability activities and surveying the users' satisfactions in each group. The $1^{\text {st }}$ stage of the research facilitated in understanding the factors related to the website structure and understanding the users' mental models.

The results of $1^{\text {st }}$ study showed interesting results from the Pakistani groups of users. The results of the study showed how the end users perceive university websites bilingually in a different way. Two websites were used for information findability. The brainstorm card sort session also reviled interesting results. The primary results provided the culturally specific preferences to with the university website in both countries. For the Pakistani group, the participants of the $1^{\text {st }}$ study intended for bilingual website with bilingual contents presentation on the same webpage which was not present in their university website. The result of the study also showed

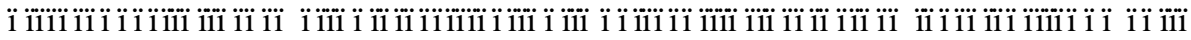

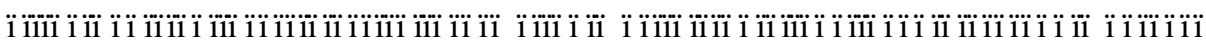

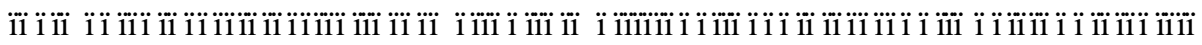

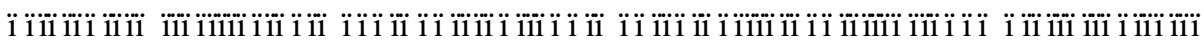

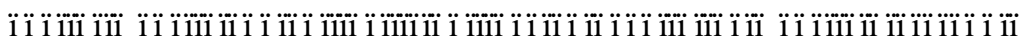

Study 2: In the second stage of the research, the card sorting activities will be revised with learning from study 1 of first stage of data collection but this time with the same website across groups. The experiments on a website for home appliance will be used to manipulate the information structure of these websites in Denmark, Pakistan and Malaysia.

\subsection{Theoretical Lenses for the Research}

In many studies, it is argued that the collective or interdependent nature of Asian society takes the contextual view of the world and believes that events are highly complex and determined by many factors such as thought process, language and cultural background [6]. On the other hand, the individualistic or independent nature of western society seems consistent with the western focus on particular objects in isolation from their context and with westerns' belief that they can know the rules governing objects and therefore can control the objects' behaviour. The difference in their approach of has an influence on the resulting product. Martine \& Rugg [7] measured the perceived similarity of webpages using a card sort technique. The card 
sorting method appears particularly well suited for a comparative and knowledge representation oriented study of information classification on a website.

\section{A Sketch of Proposed Solution}

From my $\mathrm{PhD}$ research, I intend to propose a list of factors that are involved in the information classification of websites. The study will list the factors that affect the performance of users and how they can be minimized to increase performance. The outcome of the study will provide the suggestion to avoid the bias in the interface design and information structure of the websites that is brought by the different understanding of users towards websites. This research will be helpful for software designers and web developers who are designing and developing websites and applications for Pakistan, Malaysia and Denmark. It will also be helpful for the companies who are localizing their applications in other parts of the world.

\section{References}

1. Aykin, N.: Usability and internationalization of information technology. Lawrence Erlbaum Associates, Mahwah (2005)

2. El Said, G., Hone, K.: Cross-Cultural Web Usability: An Exploration of the Experiences of Egyptians Users. In: International Workshop on Internationalisation of Products and Systems (IWIPS 2001), Milton Keynes (2001)

3. Choong, Y.-Y.: Design of computer interfaces for the chienese population, p. 180. Purude University (1996)

4. Kelly, G.: The psychology of personal constructs. Clinical Diagnosis and Psychotherapy 2 (1991)

5. Rugg, G., McGeorge, P.: The sorting techniques: a tutorial paper on card sorts, picture sorts and item sorts. Expert Systems 14(2), 80-93 (1997)

6. Nisbett, R.E.: The geography of thought: Why we think the way we do. Free Press, New York (2003)

7. Martine, G., Rugg, G.: That site looks $88.46 \%$ familiar: quantifying similarity of Web page design. Expert Systems 22(3), 115-120 (2005) 